\title{
Cervical length measurement by transvaginal sonography in predicting preterm labour in low risk women
}

\author{
Sandeep Sethumadhavan P. ${ }^{*}$, Raju Agarwal $^{2}$, \\ Jayamol M. Anilkumar ${ }^{3}$, Anup Ramchandran Pillai ${ }^{4}$
}

\begin{abstract}
${ }^{1}$ Department of Obstetrics and Gynecology, Military Hospital, Agra, Uttar Pradesh, India ${ }^{2}$ Department of Obstetrics and Gynecology, Command Hospital, Lucknow, Uttar Pradesh, India ${ }^{3}$ Department of Obstetrics and Gynecology, INHS Dhanvantari, Port Blair, India

${ }^{4}$ Assistant Manager (Statistics), State Bank of India, place, Belapur, Navi Mumbai, Maharashtra, India
\end{abstract}

Received: 10 October 2017

Accepted: 04 November 2017

\section{*Correspondence:}

Dr. Sandeep Sethumadhavan P.,

E-mail: sandeepsp5527@gmail.com

Copyright: (C) the author(s), publisher and licensee Medip Academy. This is an open-access article distributed under the terms of the Creative Commons Attribution Non-Commercial License, which permits unrestricted non-commercial use, distribution, and reproduction in any medium, provided the original work is properly cited.

\section{ABSTRACT}

Background: Preterm birth is the leading cause of perinatal morbidity and mortality. Transvaginal sonographic measurement of the cervix is a reliable alternative method for the assessment of cervical length as it allows better quality and more accurate visualization of the uterine cervix. Several studies have reported that cervical assessment on transvaginal sonography may be useful in the prediction of preterm delivery. The objective of this study was to assess cervical length at 20 to 24 weeks of gestation in low risk women and correlate with the gestational age at delivery.

Methods: A prospective cohort study conducted in a tertiary care Military Hospital in Pune, India. 354 asymptomatic low risk antenatal women with gestational age of 20 to 24 weeks were studied. Cervical assessment with transvaginal sonography for the measurement of cervical length was performed using a $10 \mathrm{MHz}$ transvaginal probe.

Results: 7 percent women delivered preterm. The incidence of short cervix in low risk women was only $0.56 \% .100 \%$ women with short cervix delivered preterm and, only $6.9 \%$ patients who had cervical length more than $25 \mathrm{~mm}$ delivered preterm. Cervical length $25 \mathrm{~mm}$ has got sensitivity and NPV of $100 \%$ and a specificity of $93.46 \%$. However, the PPV was only $8 \%$.

Conclusions: The study reported significant inverse relation between short cervix and the occurrence of preterm delivery. Our findings suggest that cervical length can be used as a screening method for preterm labour in low risk women. However strong evidences from large randomized control trials would be required to assess its costeffectiveness.

Keywords: Cervical length, Low risk women, Prediction of preterm labor, Transvaginal sonography

\section{INTRODUCTION}

PTD occurs in $5-18 \%$ of pregnancies. ${ }^{1}$ Spontaneous PTB remains the main cause of perinatal morbidity and mortality in many countries, including the USA. ${ }^{2}$ Most of the damage and death cases occur in infants delivered before 34 weeks. The incidence of early PTD $(<34$ gestational weeks) is $1-3.6 \% .^{3}$ PTD is associated with a high prevalence of severe neurological deficits and developmental disabilities and is a leading cause of infant and neonatal mortality. Mortality and morbidities, including respiratory distress syndrome, intraventricular haemorrhage, necrotizing enterocolitis and sepsis, are inversely associated with gestational age at birth., Preterm neonates are also at increased risk of developing bronchopulmonary dysplasia, patent ductus arteriosus and disorders related to gestational age at birth. ${ }^{5,6}$ Risk factors for PTD include demographic characteristics, behavioural 
factors, and aspects of obstetric history such as previous PTB. Demographic factors for PTL include black race, extremes of maternal age $(<18$ or $>35)$, low socioeconomic status, and low pre-pregnancy weight. PTL and birth can be associated with stressful life situations (e.g., domestic violence, close family death, work and home environment) either indirectly by associated risk behaviours or directly by mechanisms not completely understood. Many risk factors may manifest in the same gravida. ${ }^{7,8}$

The exact mechanism of PTL is largely unknown but is believed to include decidual haemorrhage (e.g., abruption), mechanical factors such as uterine over distension (from multiple gestation or polyhydramnios), cervical incompetence (e.g., after cone biopsy), Mullerian duct abnormalities, fibroid uterus, cervical inflammation (e.g., resulting from bacterial vaginosis), maternal inflammation and fever (e.g., urinary tract infection), hormonal changes (e.g., mediated by maternal or fetal stress), and uteroplacental insufficiency (e.g., hypertension, insulin-dependent diabetes, drug abuse, smoking, alcohol consumption). Each of these underlying causes can initiate the cascade of events that ultimately lead to uterine activity and cervical dilation. Thus, a reduction in the spontaneous PTD rate may require not only accurate identification of patients at risk for PTD but also effective treatment strategies aimed at correcting the underlying causes of PTL. ${ }^{3,7-11}$ CL measured by TVS has been shown to be an effective predictor of spontaneous PTB. ${ }^{12,13}$

The prediction of PTB has always been compromised by the lack of a reliable diagnostic test and interventions proven to delay gestation, both of which are essential for a valid screening. ${ }^{14}$ Despite these limitations, screening tests for predicting PTB, such as measurement of CL, have been proposed in response to the significant personal, societal, and economic impact of PTB. ${ }^{15}$ It has been our impression that some practitioners have misinterpreted CL measurement as a diagnostic tool, leading to interventions without proven benefit, such as cervical cerclage. ${ }^{16}$

CL screening in women with a history of prior PTB is recommended by the American college of obstetricians and gynaecologists. ${ }^{17-19}$ It remains controversial whether universal second trimester CL screening should be used as a strategy among women without prior PTB. Proponents of universal screening point to the results of two large randomized trials that demonstrated vaginal progesterone reduces the risk of PTB in women with a short cervix. ${ }^{20,21}$ Further support is garnered by two cost effective analyses, each demonstrating universal CL screening to be a cost-effective strategy to prevent PTB. Opponents of universal CL screening point to the relative rarity of a short cervix that has been found in actual clinical care and suggest that universal screening may be cost effective only in higher risk cohorts. However, we designed our study to assess the value of CL as screening test for PTB in obstetric population who are at low risk for PTB.

\section{METHODS}

This study was a prospective cohort study, carried out in a tertiary care teaching hospital of Armed Forces, India over a period of one and half years from 2015 to 2016. 354 asymptomatic patients (182 primigravidae and 178 multigravidae) attending the antenatal OPD of the hospital were included in the study. The local ethics committee approved the study protocol.

Those antenatal cases with previous history of PTD, multiple gestation in the present pregnancy, medical conditions in pregnancy like heart disease, hypertension, gestational diabetes mellitus, those conceived by the use of ART and women with any structural abnormalities of the reproductive organs were excluded from the study.

The study included all singleton pregnancies who are at low risk for PTD. 360 booked antenatal patients meeting the inclusion and exclusion criteria were studied after taking proper consent. Detailed history and examination was done. CL was measured by TVS using the $10 \mathrm{MHz}$ transducer between 20-24 weeks period of gestation.

The women were asked to empty their bladder and examination was carried out in dorsal lithotomy position. The TVS probe covered with sterile condom was inserted in the anterior fornix of the vagina until an adequate sagittal image of the cervix is visualized. The external os is identified by its triangular echo density and internal os by its ' $\mathrm{V}$ ' shaped appearance. The distance between the two is taken as CL. An adequate image for the measurement of CL was defined as the visualization of the internal os, external os and endocervical canal with at least $75 \%$ of the image occupying the screen. The CL was measured in millimeters and the measurements were taken twice. The mean of two measurements is taken as the CL for that patient.

\section{RESULTS}

A total of 442 antenatal patients were recruited in the study group after having met the inclusion/exclusion criteria and underwent CL screening between 20-24 weeks period of gestation. 37 women did not deliver at the study site and were lost to follow up. 51 patients have been excluded from the study as they have been electively terminated because of obstetrical reasons:

- Hypertensive disorders: 28

- GDM: 14

- Intrauterine growth restriction: 8

- Still birth:1

Of the 354 women with known CL and gestational age at delivery, $25(7.06 \%)$ delivered at less than 37 weeks period of gestation. 21 had spontaneous onset of PTL, 
and 4 had preterm premature rupture of membranes (PPROM). Optimal cut off values of CL for PTL have varied in various studies ranging from 18 to $30 \mathrm{~mm}$, however we took $25 \mathrm{~mm}$ as the cut off for CL which was measured between 20-24 weeks.

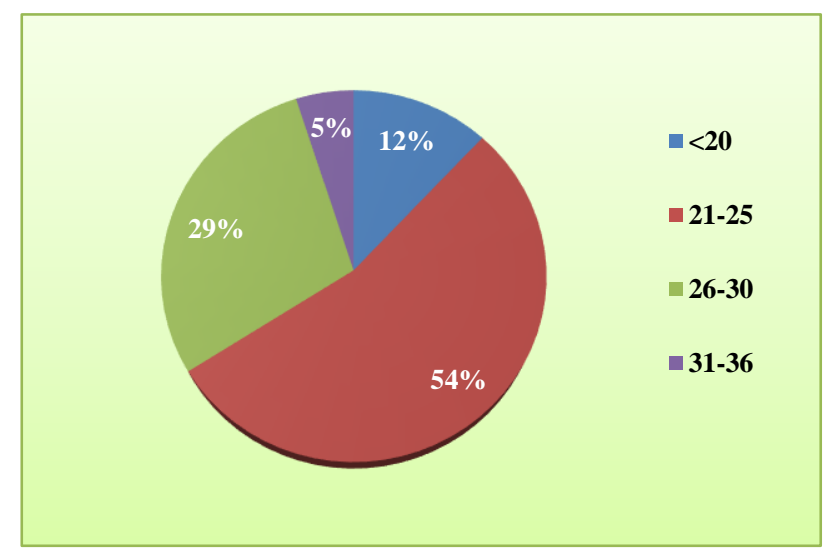

Figure 1: Pie diagram showing age wise distribution of cases in the study group.

Figure 1 shows the age distribution of patients who had undergone evaluation. $53.5 \%$ patients were in the age group of 21-25 years. Mean value of $\mathrm{CL}$ in pregnant women at 20-24 weeks of gestation in our study was 3.4 $\mathrm{cm}$.

Table 1: CL as a predictor of PTD in study group.

\begin{tabular}{|llll|}
\hline \multirow{2}{*}{ Delivery status } & CL( $(\mathbf{m m})$ & & Total \\
\cline { 2 - 4 } & $<\mathbf{2 5}$ & $\mathbf{2 5}$ & \\
\hline Preterm & 2 & 23 & 25 \\
\hline Term & 0 & 329 & 329 \\
Total & 2 & 352 & 354 \\
\hline
\end{tabular}

Table 1 shows the correlation of CL with PTD. 100\% women with $\mathrm{CL}<25 \mathrm{~mm}$ delivered preterm, however only $6.9 \%$ women with $\mathrm{CL} \geq 25 \mathrm{~mm}$ delivered preterm, making the relationship of short cervix to PTD statistically significant ( $\mathrm{P}$ value - 0.0069). The CL for predicting PTD had a sensitivity of $100 \%$ as 2 of the patients who had CL less than $25 \mathrm{~mm}$ delivered preterm. Out of the 352 patients who had CL of more than $25 \mathrm{~mm}$, 329 delivered at term, making the specificity of the test as $93.46 \%$. Out of the 25 patients who had PTD, only 2 had CL less than $25 \mathrm{~mm}$. That is the reason why we have got a low PPV of $8 \%$. All 329 patients who delivered at term had CL more than $25 \mathrm{~mm}$, leading to a very high NPV of $100 \%$. Table 2 shows that, the 2 patients, whose CL was less than $25 \mathrm{~mm}$, both had a late PTD. So, the role of prophylactic corticosteroids for fetal lung maturity in those who screen positive is debatable as per the present study. When correlation between CL and occurrence of PTD was analyzed from our data the point biserial correlation coefficient obtained was $=-0.33727$. This shows that there is fair amount of negative correlation between CL and the occurrence of PTB.

Table 2: CL in patients who had late PTD.

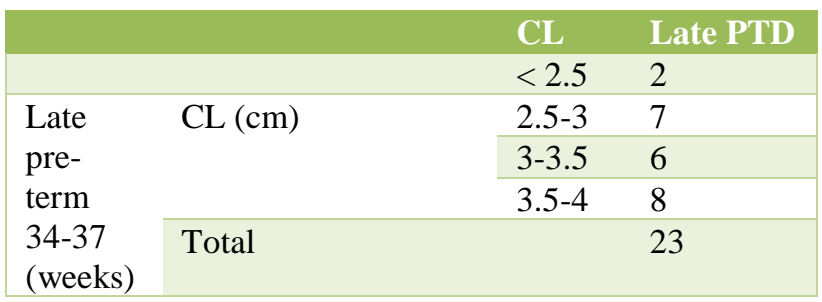

We have used the data of 354 patients and applied logistic regression analysis to find variables that are significant $(\mathrm{P}<0.05)$ for creating a model which can help in prediction of PTD (Table 3 ).

Table 3: Logistic regression analysis of variables.

\begin{tabular}{|c|c|c|c|c|c|c|}
\hline \multirow[t]{3}{*}{ Model terms } & \multicolumn{3}{|c|}{ Point estimate } & \multicolumn{3}{|c|}{ Confidence interval and p-value for beta } \\
\hline & Type & Beta & SE (beta) & $95 \% \mathrm{CI}$ & & p-value \\
\hline & & & & Lower & Upper & \\
\hline$\%$ constant & MLE & 4.55 & 2.148576116 & 1.338968055 & 9.761231669 & 0.00979 \\
\hline Gestational age & MLE & 0.000134 & 0.073215551 & -0.277447152 & 0.009552534 & 0.047326 \\
\hline Parity & MLE & -0.122 & 0.361033537 & -0.829699741 & 0.585525722 & 0.7352426 \\
\hline CL & MLE & -1.393 & 0.433363012 & -2.242836159 & -0.544084365 & 0.0013024 \\
\hline
\end{tabular}

We have considered the available variables like parity, gestational age, and CL and fitted a logistic regression model where the outcome is the occurrence of a PTD.

Using the significant terms we have created a logistic model which can help us to predict the probability of observing a PTB when the Gestational age and CL are known. The prediction model is as follows:
$\mathrm{P}=1 /[1+\exp \{-(4.55+0.000134 \times \mathrm{X} 1-1.393 \times \mathrm{X} 2)\}]$

where; P: Probability of occurrence of a PTD, X1: Gestational age in days, X2: CL in centimetre

Table 4 shows the probability of occurrence of a PTB with respect to different CLs at a gestational age of 20 weeks which is calculated using the prediction model. 
Table 4: Probability of occurrence of PTB with respect to $\mathrm{CL}$.

\begin{tabular}{|lll|}
\hline $\begin{array}{l}\text { Gestational age } \\
(\mathrm{X} 1 / 7) \text { weeks }\end{array}$ & $\mathrm{CL}(\mathrm{X} 2) \mathrm{cm}$ & $\begin{array}{l}\mathrm{P} \text { (occurrence of } \\
\text { pre-term birth) }\end{array}$ \\
\hline 20 & 1.5 & 0.922675018 \\
\hline 20 & 1.6 & 0.912132879 \\
\hline 20 & 1.7 & 0.900308763 \\
\hline 20 & 1.8 & 0.887090461 \\
\hline 20 & 1.9 & 0.872367974 \\
\hline 20 & 2 & 0.856037336 \\
\hline 20 & 2.1 & 0.838005191 \\
\hline 20 & 2.2 & 0.818194106 \\
\hline 20 & 2.3 & 0.79654844 \\
\hline 20 & 2.4 & 0.773040526 \\
\hline 20 & 2.5 & 0.747676801 \\
\hline 20 & 2.6 & 0.720503399 \\
\hline 20 & 2.7 & 0.69161064 \\
\hline 20 & 2.8 & 0.661135839 \\
\hline 20 & 2.9 & 0.629263845 \\
\hline 20 & 3 & 0.596224923 \\
\hline
\end{tabular}

\section{DISCUSSION}

CL is the most reproducible and valid variable for TVS cervical assessment in prediction of PTB. ${ }^{22}$ The addition of funneling does not improve the prediction based on CL alone. In the study by Vendittelli $\mathrm{F}$, it was seen that funneling $(>5 \mathrm{~mm})$ was not found to be predictive of PTL but CL was significantly predictive. ${ }^{23}$ In the present study we had not incorporated dynamic studies of CL for similar reasons.

We observed a sensitivity of $100 \%$ and specificity of 93.46\%. Similar results were also obtained by Shi CY et al. ${ }^{24}$ who observed $100 \%$ sensitivity with a CL of $26 \mathrm{~mm}$ as the cut off to predict the PTD among women with threatened PTL. They concluded after studying women treated for PTD, that a CL of less than $26 \mathrm{~mm}$ was a strong predictor of PTD, and intensive management is required.

The threshold for CL used in the present study was 25 $\mathrm{mm}$. However, various researchers have used different cut off values ranging from $18 \mathrm{~mm}$ to $30 \mathrm{~mm}$. Hincz $\mathrm{P}$ used two important thresholds: $20 \mathrm{~mm}$ and $31 \mathrm{~mm} .{ }^{25} \mathrm{In}$ his analysis the functional canal length $<$ or $=20 \mathrm{~mm}$ had sensitivity of $57.1 \%$, specificity of $92.6 \%$, PPV of $61.5 \%$ and NPV of $91.3 \%$. With cut off value as $31 \mathrm{~mm}$, the sensitivity was $100 \%$ with specificity of $47.1 \%$ and PPV of $28 \%$ with NPV of $100 \%$.

Pooled data suggests a cut off $30 \mathrm{~mm}$ to have sufficient sensitivity between $70-100 \%$ and would identify women who will deliver preterm. CL $>30 \mathrm{~mm}$ had NPV close to $100 \%$ for PTD. A cut off of $20 \mathrm{~mm}$ has the best positive predictive value $(70 \%){ }^{26}$ With a value of $25 \mathrm{~mm}$ we observed a good negative predictive value and high specificity as 329 of the 354 women with CL >25 mm delivered at term.

Davies et al, in a Canadian, prospective, blinded observational trial of 964 women in the general obstetrical population, found a sensitivity of $57 \%$ and a specificity of $82 \%$ for PTB, using a 30-mm cut-off at 24 to 28 weeks. ${ }^{27}$ The positive predictive value for PTB was only $4.5 \%$. We have also got a low positive predictive value of $8 \%$ as our study was also done in a low risk obstetrical population.

The ultrasound of the uterine cervix during pregnancy has been a focus of research and it has been established that the TVS of the cervix is superior to digital examination. It can detect shortening of the cervical canal before it becomes evident with manual examination. CL is the most reproducible and valid variable for cervical assessment in prediction of PTB. The addition of funneling does not improve the prediction based on CL alone. Optimal cut off lengths for prediction has also varied. However, most studies have used $25 \mathrm{~mm}$ as the cut off for CL.

The major strength of this study is that, we limited our analysis to singleton pregnancies at low risk for PTD by excluding all high-risk cases. Also, almost all patients in our prospective study were having similar socioeconomic status and education. Several important limitations must be considered when interpreting the results of the present study. Firstly, it was a single centre study. Secondly, the number of short cervix cases were only two. Thirdly, we cannot exclude the possibility of the confounding from other unmeasured covariates.

\section{CONCLUSION}

Present findings confirm those of previous studies that have found an inverse relation between the length of the cervix, as measured by TVS during pregnancy, and the frequency of PTD. It shows that there is fair amount of negative correlation between CL and the occurrence of PTB. Which means that as the CL increases the chance of PTB decreases. The shorter the cervix, the greater the likelihood of PTD. However, the CL has got a poor positive predictive value $(8.0 \%)$ in the presnt study.

The incidence of short cervix in the low risk group was very less $(0.56 \%)$. From the present data, short cervix is a good predictor of PTB and can be used as a screening method for prediction of PTL.

But as the incidence of short cervix is very less in low risk obstetric population, further large multicentric studies including cost-effectiveness studies are needed to consider universal CL screening in low risk women.

Funding: No funding sources

Conflict of interest: None declared 
Ethical approval: The study was approved by the Institutional Ethics Committee

\section{REFERENCES}

1. Blencowe H, Cousens S, Oestergaard M, Chou D, Moller AB, Narwal R, et al. National, regional and worldwide estimates of preterm birth. The Lancet. 2012;379(9832):2162-72.

2. Hamilton BE, Martin JA, Osterman MJ, Curtin SC, Matthews TJ. Births: final data for 2014. Natl Vital Stat Rep. 2015;64:1-64.

3. Goldenberg RL, Culhane JF, Iams JD, Romero R. Epidemiology and causes of preterm birth. The Lancet. 2008;371:75-84.

4. Treyvaud K. Parent and family outcomes following very preterm or very low birth weight birth: a review. Semin Fetal Neonatal Med. 2014;19:131-5.

5. Buchanan SL, Crowther CA, Levett KM, Middleton P, Morris J. Planned early birth versus expectant management for women with preterm prelabour rupture of membranes prior to 37 weeks' gestation for improving pregnancy outcome. Cochrane Database Systematic Rev. 2010;3:CD004735.

6. Stoll BJ, Hansen NI, Bell EF. Neonatal outcomes of extremely preterm infants from the NICHD Neonatal Research Network. Pediatr. 2010;126:443-6.

7. Celik E, To M, Gajewska K, Smith GCS, and Nicolaides KH. Cervical length and obstetric history predict spontaneous preterm birth: development and validation of a model to provide individualized risk assessment. Ultrasound Obstet Gynecol. 2008;31:54954.

8. Iams JD, Berghella V. Care for women with prior preterm birth. Am J Obstet Gynecol. 2010;203:89-100.

9. Rackow BW, Arici A. Reproductive performance of women with Mullerian anomalies. Current Opinion Obstet Gynecol. 2007;19:229-37.

10. Donders GG, Calsteren VK, Bellen G. Predictive value for preterm birth of abnormal vaginal flora, bacterial vaginosis and aerobic vaginitis during the first trimester of pregnancy. Br J Obstet Gynaecol. 2009;116:1315-24.

11. Lamont RF, Taylor-Robinson D. The role of bacterial vaginosis, aerobic vaginitis, abnormal vaginal flora and the risk of preterm birth. Br J Obstet Gynaecol. 2010;117:119-20.

12. Hernandez-Andrade E, Romero R, Ahn H, Hussein Y, Yeo L, Korzeniewski SJ, et al. Transabdominal evaluation of uterine cervical length during pregnancy fails to identify a substantial number of women with a short cervix. J Matern Fetal Neonatal Med. 2012;25:1682-9.

13. Berghella V, Baxter JK, Hendrix NW. Cervical assessment by ultrasound for preventing preterm delivery. Cochrane Database Syst Rev. 2013;31:CD007235.

14. Sackett DL, Haynes RB, Guyatt GH, Tugwell P. Early diagnosis. Clinical epidemiology: a basic science for clinical medicine. $2^{\text {nd }}$ ed. Boston: Little, Brown and Company; 1991:153-70.

15. Iams JD, Goldenberg RL, Meis PJ, Mercer BM, Moawad A, Das A, et al. The length of the cervix and the risk of spontaneous premature delivery. N Engl J Med. 1996;334:567-72.

16. Belej-Rak T, Okun N, Windrim R, Ross S, Hannah ME. Effectiveness of cervical cerclage for a sonographically shortened cervix: a systematic review and metaanalysis. Am J Obstet Gynecol. 2003;189:1679-87.

17. Schaaf JM, Hof MF, Mol B, Abu-Hanna A, Ravelli AC. Recurrence risk of preterm birth in subsequent twin pregnancy after preterm singleton delivery. BJOG. 2012;119(13):1624-9.

18. Khandelwal M. Vaginal progesterone in risk reduction of preterm birth in women with short cervix in the mid trimester of pregnancy. Int $\mathrm{J}$ Womens Health. 2012:4:481-90.

19. Prediction and prevention of preterm birth. Practice Bulletin No. 130. American college of Obstetricians and Gynecologists. Obstet Gynaecol. 2012;120:964-7.

20. Fonseca EB, Celik E, Parra M, Singh M. Fetal medicine foundation second trimester screening group. Progesterone and the risk of preterm birth among women with a short cervix. $N$ Engl $J$ Med. 2007;357:462-9.

21. Hassan SS, Romero R, Vidyadhari D, Fusey S, Baxter JK, Khandelwal M, et al. Vaginal progesterone reduces the rate of preterm birth in women with a sonographic short cervix: a multicenter, randomized, double-blind, placebo-controlled trial. Ultrasound in Obstet Gynecol. 2011;38(1):18-31.

22. Berghella V, Bega G, Tolosa JE, Berghella M. Ultrasound assessment of the cervix. Clin Obstet Gynecol. 2003;46:947-62.

23. Vendittelli F, Malle N, Munoz F. Transvaginal ultrasonography of the uterine cervix in hospitalized women with preterm labor. Int J Obstet Gynecol. 2001;72:117-25.

24. Shi Cy, Zhang YY, Jin Yz, Dong Y.Study of the cervix of normal pregnancy and threatened preterm delivery using trans vaginal sonography. Obstet Gynecol Clin North Am. 2005;32:383-96.

25. Hincz P, Wilczynski J, Kozarzewski M, Szaflik K. Trans vaginal sonography in prediction of preterm delivery in patients presenting with signs and symptoms of preterm labor. Ginekol Pol. 2001;72:778-82.

26. Berghella V, Ness A, Bega G, Berghella M. Cervical sonography in women with symptoms of preterm labor. Obstet Gynecol Clin N Am. 2005;32:383-96.

27. Davies G, Ottenhof C, Woodman M, Farley A, Julien $\mathrm{N}$, Van VD, et al. Cervix length and relaxing as predictors of preterm birth. J Obstet Gynaecol Can. 2008;30:1124-31.

Cite this article as: Sethumadhavan SP, Agarwal R, Anilkumar JM, Pillai AR. Cervical length measurement by transvaginal sonography in predicting preterm labour in low risk women. Int $\mathbf{J}$ Reprod Contracept Obstet Gynecol. 2017;6:5563-7. 